\title{
Generalization of a Capaldi sequential analysis to the aversive case
}

\section{JAMES H. REYNIERSE and ROGER G. STRAW* Hope College, Holland, Mich. 49423}

Using an incentive model of avoidance learning in which intertrial interval was manipulated to provide nonrewards (N), small rewards (S), or large rewards (L), specific sequences of rewards were generated. A SNNL sequence yielded better shuttlebox avoidance than a LNNS sequence for the same intertrial interval, but only when intertrial interval was relatively long.

Implicit in Capaldi's (1966, 1967, 1970, 1971) sequential analysis of the partial reinforcement effect is the idea that sequence of reward is a major conditioning variable with broad applicability within a general theory of learning. However, with the exception of the present study, obtained sequence effects have largely been restricted to runway procedures under appetitive reinforcement conditions. The present investigation combined a sequential analysis with an incentive variable derived from Denny's (Denny, 1971; Weisman, Denny, \& Zerbolio, 1967) relaxational interpretation of avoidance learning to produce a sequence effect when the intertrial interval was long.

The partial reinforcement effect refers to the greater resistance to extinction which occurs when an instrumental response, such as traversing a runway, is reinforced only part of the time compared to a training procedure in which the response is always reinforced. Since animals which receive large rewards exhibit greater resistance to extinction than those which receive small rewards (Hulse, 1958; Wagner, 1971), some theorists have argued that resistance to extinction is a function of magnitude of partial reinforcement, e.g., Amsel (1958, 1967) and Lawrence \& Festinger (1962). The sequential hypothesis, however, states that resistance to extinction is due to the magnitude of reward contained in the transition from nonrewarded trials to rewarded trials, i.e., resistance to extinction is increased only if a large reward trial follows a nonrewarded trial (Capaldi, 1966, 1967, 1970, 1971).

Conceptually, generalization to the aversive case is somewhat ambiguous, since it is unclear what constitutes either partial reinforcement or a large reward avoidance learning task. For example, avoidance learning procedures usually include presenting a warning signal which is followed by an escapable and avoidable shock US. Particularly under conditions where animals are avoiding efficiently, extended acquisition of avoidance resembles partial reinforcement conditions, since the shock US is rarely present (Sheffield \& Temmer, 1950), but also resembles extinction procedures which

* Roger B. Straw was a participant in NSF-URP Grant GY-10022. systematically withhold shock (Baum, 1970; Reynierse \& Rizley, 1970). For these reasons, the present sequential analysis was directed to acquisition rather than to extinction of avoidance.

How we view magnitude of reward in avoidance learning depends on whether onset or termination of the shock US is considered the source of reinforcement. If shock onset, then presumably shock intensity or duration could be systematically manipulated, but only on escape trials when an animal's failure to make an avoidance response produces the required shock trial. But such dependence upon an animal's performance does not easily lend itself to a sequential analysis, for it is unlikely to produce systematically the required sequences. In contrast, viewing shock termination and the postshock interval as the source of reinforcement is theoretically justified (Denny, 1971) and permits employing a methodologically reliable procedure for arranging reward sequences. There is a considerable amount of evidence that long intertrial intervals, that is, long time-outs from shock, facilitate acquisition of avoidance. For our purposes, the empirical data, which are consistent with what Denny (1971) has called long-latency relaxation and which facilitate acquisition of avoidance, can be viewed as positive incentives. In general, short intertrial intervals and time-outs from shock can be viewed as small rewards, while longer intervals can be viewed as large rewards.

\section{METHOD \\ Subjects}

The Ss were 32 adult albino rats, 16 males and 16 females. The rats were maintained two per cage, with ad lib food and water. Subsequently, they were assigned at random to four groups of four males and four females each.

\section{Apparatus}

The apparatus, two identical $36 \times 4 \times 14$ in. automated shuttleboxes, were constructed of clear Plexiglas and were housed in sound-attenuating enclosures. Shock of $1.3 \mathrm{~mA}$ was delivered to the stainless steel grid floors by Grason-Stadler shock scramblers. A Sonalert tone source on the top of each box produced a 2800 -cps tone at $85 \mathrm{~dB}$. Running responses were monitored, by a photocell system, while programming and recording were achieved by appropriate relay circuitry.

\section{Procedure}

Rats remained undisturbed for a 30-min adaptation period when placed in the apparatus prior to acquisition procedures. For all animals in all conditions the CS-US interval was $5 \mathrm{sec}$, both the tone CS and shock US being response terminated when an animal ran from one end of the shuttlebox to the other.

The experimental design consisted of two levels of sequence (SNNL or LNNS) orthogonal to two magnitudes of nonreward $(\mathrm{N})$, small reward (S), and large reward (L) trials, with eight rats in each of the four experimental conditions. These magnitudes were either $N$ of $20 \mathrm{sec}, S$ of $40 \mathrm{sec}$, and $\mathrm{L}$ of $80 \mathrm{sec}$ or $\mathrm{N}$ of $40 \mathrm{sec}, \mathrm{S}$ of $80 \mathrm{sec}$, and $\mathrm{L}$ of $160 \mathrm{sec}$. Thus, while the ratio of $\mathrm{L}$ 
Table 1

Means and Standard Deviations of Response Measures as a Function of Sequence and Magnitude of Reward

\begin{tabular}{|c|c|c|c|c|c|c|c|c|c|c|c|}
\hline \multicolumn{2}{|c|}{ Condition } & \multicolumn{2}{|c|}{$\begin{array}{c}\text { Avoidances Per } \\
\text { Session } \\
\end{array}$} & \multicolumn{2}{|c|}{$\begin{array}{c}\text { Avoidances Per } \\
100 \text { Trials } \\
\end{array}$} & \multicolumn{2}{|c|}{$\begin{array}{c}\text { Trials to } \\
\text { Acquisition }\end{array}$} & \multicolumn{2}{|c|}{ US Duration } & \multicolumn{2}{|c|}{ CS Duration } \\
\hline Sequence & Magnitude & Mean & SD & Mean & SD & Mean & SD & Mean & SD & Mean & SD \\
\hline $\begin{array}{l}\text { SNNL } \\
\text { LNNS } \\
\text { SNNL } \\
\text { LNNS }\end{array}$ & $\begin{array}{l}40-20-20-80 \\
80-20-20-40 \\
80-40-40-160 \\
160-40-40-80\end{array}$ & $\begin{array}{c}125.75 \\
149.75 \\
135.5 \\
75.62\end{array}$ & $\begin{array}{l}42.54 \\
28.27 \\
42.39 \\
48.53\end{array}$ & $\begin{array}{l}51.38 \\
59.25 \\
63.5 \\
24.12\end{array}$ & $\begin{array}{l}23.16 \\
23.27 \\
23.21 \\
20.34\end{array}$ & $\begin{array}{r}70.25 \\
56.62 \\
58.38 \\
140.75\end{array}$ & $\begin{array}{l}52.12 \\
30.01 \\
55.79 \\
59.0\end{array}$ & $\begin{array}{c}69.45 \\
65.45 \\
70.8 \\
169.05 \\
\end{array}$ & $\begin{array}{l}43.94 \\
43.24 \\
63.53 \\
81.77 \\
\end{array}$ & $\begin{array}{l}747.56 \\
668.06 \\
723.27 \\
955.51 \\
\end{array}$ & $\begin{array}{l}185.22 \\
147.58 \\
206.92 \\
269.98 \\
\end{array}$ \\
\hline
\end{tabular}

to $\mathrm{S}$ to $\mathrm{N}$ trials was the same 4 to 2 to 1 relationship for both magnitude of reward conditions, average magnitude of reward as expressed in the intertrial interval sequences did vary. Since $\mathrm{N}$ length always equaled two (SNNL and LNNS), the mean intertrial interval was either 40 or $80 \mathrm{sec}$ for the two magnitude of reward conditions. Within the 200-trial session, each set of four trials cycled repetitively.

\section{RESULTS AND DISCUSSION}

The results, summarized in Table 1 , were analyzed by analysis of variance. For cumulative avoidances over the entire sessions, the effect for magnitude of reward was significant $(\mathrm{F}=4.29, \mathrm{df}=1 / 28, \mathrm{p}<.05)$ and it interacted with sequence $(\mathrm{F}=7.28, \mathrm{df}=1 / 28, \mathrm{p}<.02)$. These results reflect a sequence effect and SNNL superiority for large magnitudes of reward but with overall superiority for the shorter magnitude of reward conditions. Essentially the same relationship was obtained for frequency of avoidances over the first 100 trials and for trials to reach a conventional acquisition criterion of 9 out of 10 avoidances. Again, magnitude of reward interacted with sequence $(\mathrm{F}=7.7, \mathrm{df}=1 / 28$, $\mathrm{p}<.01$ and $\mathrm{F}=6.58, \mathrm{df}=1 / 28, \mathrm{p}<.02$, respectively). Cumulative duration of the shock US over 200 trials yielded significant effects for sequence $(F=4.28$, $\mathrm{df}=1 / 28, \mathrm{p}<.05)$, magnitude of reward $(\mathrm{F}=5.31$, $\mathrm{df}=1 / 28, \mathrm{p}<.05)$, and their interaction $(\mathrm{F}=5.04$, $\mathrm{df}=1 / 28, \mathrm{p}<.05)$. These results are consistent with the avoidance data and again reflect SNNL superiority for large magnitudes of reward. Analysis of the cumulative duration of the tone CS did not yield any significant relationships. The obtained results are internally consistent with the LNNS sequence for high magnitude of reward (160-40-40-80), showing fewer avoidances, taking many more trials to reach criterion, and receiving a larger amount of shock than each of the other experimental conditions.

These results support the generality of a sequential analysis and suggest that sequence of reward has important implications for the aversive case. They also demonstrate that combining a sequential analysis with an incentive analysis has considerable promise for future investigations of avoidance learning. That a sequence effect was only obtained for long intertrial intervals suggests that the mechanisms underlying sequence effects in avoidance learning may be complicated by emotional variables, rather than the primary memory process proposed by Capaldi (1971). Furthermore, it is also clear that, to the extent that there is a sequence effect, it is strictly a decremental effect in which performance in the LNNS group is considerably poorer than that obtained in the other groups. One possible interpretation of such a decremental effect is that small reward trials in the LNNS condition are always followed by and contrasted to a very large 160 -sec reward under long intertrial interval conditions. According to relaxation theory (Denny, 1971), the crucial event mediating both acquisition and extinction of avoidance is the unconditioned response of relaxation-approach which occurs in the safe compartment or safe period following the removal of an aversive stimulus. Since relaxation as a response is incompatible with the fear responses elicited by the shock cues, contrast effects may maximize relaxational responses when intertrial interval is long, thereby accounting for the obtained decrement under LNNS conditions for long intertrial intervals.

\section{REFERENCES}

Amsel, A. The role of frustrative nonreward in noncontinuous reward situations. Psychological Bulletin, 1958, 55, 102-119. Amsel, A. Partial reinforcement effects on vigor and persistence. In $\mathrm{K}$. W. Spence and J. T. Spence (Eds.), The psychology of learning and motivation: Advances of research and theory. Vol. 1. New York: Academic Press, 1967.

Baum, M. Extinction of avoidance responding through response prevention (flooding). Psychological Bulletin, 1970, 74, 276-284.

Capaldi, E. J. Partial reinforcement: A hypothesis of sequential effects. Psychological Review, 1966, 73, 459-477.

Capaldi, E. J. A sequential hypothesis of instrumental learning. In K. W. Spence and J. T. Spence (Eds.), The psychology of learning and motivation: Advances in research and theory. Vol. 1. New York: Academic Press, 1967.

Capaldi, E. J. An analysis of the role of reward and reward magnitude in instrumental learning. In $J$. H. Reynierse (Ed.), Current issues in animal learning. Lincoln: University of Nebraska Press, 1970.

Capaldi, E. J. Memory and learning: A sequential viewpoint. In W. Honig and P. H. R. James (Eds.), A nimal memory. New York: Academic Press, 1971.

Denny, M. R. Relaxation theory and experiments. In F. R. Brush (Ed.), Aversive conditioning and learning. New York: Academic Press, 1971.

Hulse, S. H. Amount and percentage of reinforcement and duration of goal confinement in conditioning and extinction. Journal of Experimental Psy chology, 1958, 56, 48-57.

Lawrence, D. H., \& Festinger, L. Deterrents and reinforcement. Stanford: Stanford University Press, 1962.

Reynierse, J. H., \& Rizley, R. C. Stimulus and response contingencies in extinction of avoidance by rats. Journal of Comparative \& Physiological Psychology, 1970, 73, 86-92.

Sheffield, F. D., \& Temmer, H. W. Relative resistance to extinction of escape training and avoidance training. Journal of Experimental Psychology, 1950, 40, 287-298.

Wagner, A. R. Effects of amount and percentage of reinforcement and number of acquisition trials on conditioning and extinction. Journal of Experimental Psychology, 1961, 62, 234-242.

Weisman, R. G., Denny, M. R., \& Zerbolio, D. J. Discrimination based on differential nonshock confinement in a shuttle box. Journal of Comparative \& Physiological Psychology, 1967, 63, 34-38.

(Received for publication February 26, 1973.) 